\title{
QUALITY EVALUATION OF TIGERNUT MILK-BASED POPSICLES PRODUCED WITH DATE PALM FRUITS AS SWEETENER
}

\author{
- Research paper -
}

\author{
Jumoke Bukola ADELOYE ${ }^{1}$, Precious UHAKHEME
}

Department of Food Science and Technology, Federal University of Technology Akure, Nigeria

\begin{abstract}
Popsicle is a flavored and edible ice on stick that can be produced with dairy products. This study aimed to investigate the possibility of using milk from tigernut as a non-dairy source and date palm fruits as sweetener for producing popsicles with enhanced bioactive properties and acceptability. Tigernut milk-based popsicles sweetened with sugar, unroasted date or roasted date were made. The physical properties, antioxidant activity, total phenolic content, melting rate, and sensory characteristics were evaluated. The roasting process significantly influenced the total phenol, antioxidant activity and sensory characteristics of the popsicles. Melting resistance was higher in the popsicles containing both the roasted and unroasted dates compared to the sugar sweetened popsicles. Popsicles sweetened with roasted dates exhibited the most acceptable sensory properties in terms of flavour, taste and overall acceptability.
\end{abstract}

Keywords: Popsicles, Roasted date, Antioxidant capacity, Tigernut milk, Melting rate.

\section{INTRODUCTION}

Popsicle is a frozen pop on stick that can either be milk-based or water-based. A dairy product including whey concentrate was used for the production of popsicles with good sensory attributes (Gajo et al. 2017). Fruity flavored popsicles are made from mixtures of different fruits and other materials added to enhance its texture and taste. Popsicles manufactured with water melon juice resulted in a product rich in bioactive compounds that are linked with health benefits (Martins et al, 2018). It can serve as a hydration drink and more so it is cherished across all age groups. Sugar is added to sweeten popsicles. However, the increasing health issues with added sugars in food and drink has continuously posed a major concern to consumers. Thus, an alternative sweetener with nutritional and functional properties is required in the food industry in order to reduce added sugars to food.

Tigernut is a rhizome that is eaten in different forms; raw, dried, baked, roasted or processed into refreshing beverage. The yellow and brown varieties are common in Nigeria whereas the yellow is preferred because of its size, colour and flesh.

Tigernut milk is a suitable as alternative beverage for celiac patients who are intolerant to gluten and lactose. It has high nutritional qualities and

Received: 25.06.2019.

Accepted in revised form: 1.12 .2019 potential health beneficial bioactive compounds. However, tigernut still remains underutilized in Nigeria.

The date palm fruit (Phoenix dactylifera L.) is common in the Middle East nations and utilized as staple food. The fruit is rich in fiber, made up of $8.3-29.5 \mathrm{~g} / 100 \mathrm{~g}$ moisture, $0.1-0.5 \mathrm{~g} / 100 \mathrm{~g}$ lipid content and $1.6-2.5 \mathrm{~g} / 100 \mathrm{~g}$ protein content in the dry form (Borchani et al., 2010). Essential mineral elements are present in date palm fruits (Al Farsi and Lee, 2008).In addition, high level and diverse phenolic compounds are abundant in the date palm fruits with great antioxidant activities (El Sohaimy et al., 2015). However, the fruits are under exploited and require more research attention. Being a good source of simple sugar such as glucose and fructose, it could be exploited as alternative sweeteners in foods and drinks thereby reducing added sugars in food products and averting health risk including obesity and diabetes. There is an increasing agitation for a reduction of sugar added to food as well as desire for potential health benefits compounds in consumed foods. Unfortunately, popsicles are sweetened with sugar and lacking in substantial functional compounds. Hence, this study is aimed at preparing popsicles with non-dairy based ingredients (tigernut milk) and alternative sweetener (roasted and unroasted dates), and to assess the effects of the dates in its roasted and unroasted form on the sensory properties, physicochemical and antioxidant activity of tigernut milk-based popsicles.

\footnotetext{
${ }^{1}$ Corresponding author. E-Mail address: bolatujoye@,futa.edu.ng
} 


\section{MATERIALS AND METHODS}

\section{Materials}

Tiger nuts (yellow variety) and date palm fruits were obtained from a neighborhood market in the city of Akure, Ondo State, Nigeria. The tiger nuts as well as the dates palm fruits were selected and cleaned after screening to remove stones, foreign materials, dirt and infestation. By filtration using a clean muslin cloth, milk was extracted from the soaked and milled tigernuts. The date palm fruits were deseeded by cutting into two halves using a clean knife and removing the seed inside. A portion of the deseeded dates was roasted at a high temperature for $50 \mathrm{~min}$ in an oven. The roasted and unroasted dates were ground, packed and stored for further analysis.

\section{Production of ice popsicles}

The popsicle ingredients were measured and blended together (Table 1) using a heavy duty blender for thorough mixing to avoid lumps especially from the carboxyl methylcellulose (CMC) which was slowly incorporated. Afterwards, the formulations were pasteurized at $65^{\circ} \mathrm{C}$ for $30 \mathrm{~min}$, poured into the sterilized pop molds and subjected to freezing. Plastic popsicle sticks were inserted when freezing commenced. After complete freezing, popsicles were removed from molds and stored away frozen. Sugar sweetened popsicles was used as control (SGR), Unroasted date sweetened popsicles (UDP) and Roasted date sweetened popsicles (RDP) were made. Popsicles were thawed at $4^{\circ} \mathrm{C}$ and properly mixed for analyses.

\section{Physicochemical properties of popsicles}

Proximate composition of the popsicles including moisture, crude fat, crude ash and crude protein, were determined as described by AOAC (2005). Total carbohydrates were calculated by the difference. The $\mathrm{pH}$, total soluble solids (Brix) and titrable acidity were determined using the $\mathrm{pH}$ meter, refractometer and titration method with $\mathrm{NaOH}$ solution respectively.

\section{Folin-Ciocalteu method for total polyphenol content}

Folin-Ciocalteu method according to Georgé, et al. (2005) with modification was used to carry out the phenolic content analysis and using gallic acid as standard. The samples were extracted with aqueous ethanol and an aliquot of $50 \mu \mathrm{l}$ extract was used for the analysis. To the aliquot were added $3 \mathrm{ml}$ of distilled water and $250 \mu \mathrm{l}$ of Folin-Ciocalteu reagent. The mixture was thoroughly mixed and allowed to stand for $5 \mathrm{~min}$. Thereafter, $750 \mu \mathrm{l}$ of $20 \%$ sodium carbonate solution $\left(\mathrm{Na}_{2} \mathrm{CO}_{3}\right)$ was added, and then proper mixing was done, left for $30 \mathrm{~min}$. at room temperature, after which absorbance was taken at $760 \mathrm{~nm}$ with the use of a spectrophotometer and compared with gallic acid calibration curve. The result was shown as gallic acid equivalents (mg GAE/L).

\section{Colorimetric method for total flavonoid content determination}

The determination of the flavonoids quantity in the popsicles was performed by the aluminum chloride colorimetric assay in accordance to the method of Chang et al (2002). After extraction with aqueous ethanol, a mixture consisting of $0.5 \mathrm{ml}$ of the extract, $1.5 \mathrm{ml}$ of pure ethanol, $0.1 \mathrm{ml}$ of potassium acetate $(1 \mathrm{M}), 0.1 \mathrm{ml}$ of $10 \%$ aluminum chloride and $3 \mathrm{ml}$ of distilled water was made after a rigorous mixing. Then mixture was allowed to stand for $30 \mathrm{~min}$. at room temperature. The absorbance at $415 \mathrm{~nm}$ was recorded using a spectrophotometer and compared with a standard calibration curve of quercertin solution.

\section{Determination of mineral composition}

The mineral constituents of the samples including iron, zinc, calcium, sodium, potassium and manganese were determined by using the flame atomic absorption spectrophotometer.

Table 1. Formulation of Tiger nut milk-based popsicles

\begin{tabular}{|l|l|l|l|}
\hline INGREDIENTS & SGP & UDP & RDP \\
\hline Tiger nut milk (ml) (\%v/v) & 88.8 & 88.8 & 88.8 \\
\hline CMC (\%w/v) & 0.2 & 0.2 & 0.2 \\
\hline Sugar (\%w/v) & 11 & - & - \\
\hline Unroasted date(\%w/v) & - & 11 & - \\
\hline Roasted date (\%w/v) & - & - & 11 \\
\hline
\end{tabular}

CMC- carboxyl methyl cellulose, SGP-sugar sweetened popsicle, UDP- unroasted date sweetened popsicle and RDProasted date sweetened popsicle 


\section{Free radical scavangingcapacity}

The presence of varieties of bioactive components in date palm fruits suggests antioxidant potentials. Therefore, the antioxidant capacity of the popsicles was quantified by free radicals scavenging method and power to reduce iron (III) to iron (II).

\section{1,1-diphenyl-2-picrylhydrazyl (DPPH) test}

The antioxidant ability of the popsicles by free radicals scavenging method was determined as described by Gyamfi et al. (1999) with some modifications where $0.2 \mathrm{ml}$ aliquot of extracts from aqueous ethanolic extraction was mixed with $3.8 \mathrm{ml}$ of DPPH solution $(0.004 \%)$ in methanol. Homogenous mixture obtained after rigorous mixing was kept in darkness for 1 hour at room temperature. The absorbance was read at $517 \mathrm{~nm}$ using the spectrophotometer and then the calculation of the ability to scavenge DPPH radicals was done.

\section{Ferric reduction power test}

The method of Oyaizu (1986) was used to quantify the reducing power of the tested samples as follows: an homogenous mixture of extracts $(1 \mathrm{ml})$, sodium phosphate buffer $(1 \mathrm{ml}, 200 \mathrm{mM}, \mathrm{pH} 6.6)$ and potassium ferric cyanide $(1 \mathrm{ml})$ was made and kept for $20 \mathrm{~min}$ at $50^{\circ} \mathrm{C}$. Thereafter, $10 \%$ trichloroacetic acid $(1 \mathrm{ml})$ was introduced into the mixture, mixed and centrifuged for $10 \mathrm{~min}$ at 3000 rpm. $0.4 \mathrm{ml}$ of ferric chloride $(0.1 \%)$ was introduced into the mixture of $2 \mathrm{ml}$ of supernatant and $2 \mathrm{ml}$ of distilled water then absorbance was taken at $700 \mathrm{~nm}$. Result was expressed as $\mathrm{mg}$ ascorbic equivalent $/ \mathrm{g}$ of sample.

\section{Determination of abts $^{+}$radical scavenging capacity}

The ABTS test was used to determine the ability of the popsicles samples to scavenge ABTS cationic radicals in accordance to the procedure described by $\mathrm{Re}$ et al (1999) with modifications. The generation of ABTS free radicals was done by the reaction of two solutions; $7 \mu \mathrm{M}$ ABTS stock solution and $2.45 \mu \mathrm{M}$ potassium per sulfate solution. The resulting mixture was left at room temperature for 12-16 hours in the darkness. The mixture was diluted with distilled water to get an absorbance reading of $0.700 \pm 0.005$ at $734 \mathrm{~nm}$. A mixture of $3000 \mu \mathrm{l}$ of the ABTS radical solution adjusted to an absorbance of $0.700 \pm 0.005$ and $200 \mu 1$ of the sample was made and left for 6 min at room temperature before reading the absorbance at $734 \mathrm{~nm}$ immediately using a spectrophotometer and being compared with a calibration curve generated with a Trolox solution.

\section{Melting rate}

The melting rate was determined as described by Soukoulis, Chandrinos and Tzia, (2008) at room temperature $\left(25 \pm 0.5^{\circ} \mathrm{C}\right)$. Popsicle samples $(90 \mathrm{~g})$ were transferred on a suspended metal screen on a beaker placed on an analytical weighing balance. The popsicles that melted and dropped between 0 and 40 minutes at every ten minutes interval was weighed and plotted against time. The rate at which the popsicles melted was calculated and expressed in $\mathrm{g} \cdot \mathrm{min}^{-1}$.

\section{Sensory evaluation}

All randomly encoded tigernut milk-based popsicles sweetened with sugar, unroasted or roasted dates $(50 \mathrm{~g})$ were presented to the untrained panelists in white disposable cups to evaluate for flavor, taste, appearance, color, aroma, aftertaste, and overall acceptability using a hedonic scale of nine points and scoring from dislike very much to like extremely.

\section{Statistical analysis}

Data obtained were expressed as mean \pm standard deviation (S.D.), analysed by analysis of variance (ANOVA) and comparison between means were carried out using the Duncan test at 95\% confidence level. The SPSS statistical software version 20 was used for the analyses of experimental results.

\section{RESULTS AND DISCUSSION}

\section{Nutritional and physical characteristics of popsicles}

Proximate composition of the manufactured tigernut milk-based popsicles sweetened with sugar, unroasted date or roasted date is shown in Table 2 . The popsicles had protein content ranging from $0.5 \%$ in SGP to $0.71 \%$ in UDP. A similar finding to our result was reported by Carolina et al
(2018) in water melon flavored popsicles. Dates palm fruit is relatively low in protein (Al-Farsi and Lee, 2011). The variation in the amount of protein shown in the popsicles may be due to the roasting process that date was subjected to (Oboh et al., 2010). Denaturation of protein during the roasting operation might be responsible for the low protein in RDP samples. It has been reported that roasting process can affect both chemical and nutritional composition of food products (Olivero et al., 
2009). UDP had significantly high crude fat than SGP and RDP samples. This finding corroborates the observation of Oracz and Nebesny (2018) on the roasting of cocoa beans. Degradation of lipids occur at high temperature (Choe and Min, 2008). Ash content was similar in all the popsicles and ash suggests the presence of organic nutrients in the popsicles (Ndife et al., 2013). Carbohydrate contents of RDP samples was significantly lower than the SGP and UDP samples. The reduction may be due to the participation of the sugar components in Mallard reaction during roasting operation of the date palm fruit. Moisture content was significantly higher in RDP samples while it was lowest in the SGP samples. Table 3 shows the TTS, pH and TTA of the popsicles. TTS were higher in the SGP samples than the RDP and UDP samples. Titratable acidity was similar for all the popsicles and not affected by roasting. RDP and UDP showed lower $\mathrm{pH}$ values compared to SGP.

Table 4 shows the mineral contents of SGP, UDP and RDP samples. Sodium is the dominant mineral element in the popsicles. There was a significant difference in iron, sodium and potassium between UDP and RDP samples. Roasting increased the level of $\mathrm{Na}, \mathrm{Fe}$ and $\mathrm{K}$ in the popsicles. Fe plays an important role in blood cell formation. An increase in $\mathrm{Na}$ was also reported in roasted maize varieties (Oboh et al., 2010). $\mathrm{Zn}, \mathrm{Mn}$ and $\mathrm{Ca}$ were not affected by roasting. Calcium is essential for bone formation.

Recently, studies have associated various health benefits to polyphenols including preventing degenerative diseases (Taylor and Duodu, 2015). The results of polyphenols and flavonoids content are shown in Fig ures 1A\&B. The TPC was higher in UDP when compared to RDP samples. Similar findings were seen for TFC, with values of 20.58 $\mathrm{mgQE} / \mathrm{g}$ for UDP and 11.24 and $20.05 \mathrm{mgQE} / \mathrm{g}$ for RDP and SDP respectively. This outcome suggests that the roasting operation resulted in a reduction in the bioactive compounds (TPC and TFC) of the roasted dates compared to the unroasted dates. Decrease in total polyphenol in sorghum grain, maize as well as in coffee due to roasting have been reported in some research works (Irondi et al., 2019; Oboh et al., 2010; Vignoli et al., 2014). These bioactive compounds might have been degraded by high temperature during roasting or are thermolabile (Irondi et al., 2019; Lemos et al., 2012).

Table 2. Proximate Composition of Popsicle

\begin{tabular}{|l|l|l|l|}
\hline Contents \% & SGP & UDP & RDP \\
\hline Moisture & $77.9 \pm 1.62^{\mathrm{c}}$ & $81.34 \pm 0.27^{\mathrm{b}}$ & $83.53 \pm 0.02^{\mathrm{a}}$ \\
\hline Fat & $0.78 \pm 0.02^{\mathrm{c}}$ & $2.02 \pm 0.02^{\mathrm{a}}$ & $1.45 \pm 0.01^{\mathrm{b}}$ \\
\hline Protein & $0.51 \pm 0.01^{\mathrm{c}}$ & $0.71 \pm 0.01^{\mathrm{a}}$ & $0.62 \pm 0.30^{\mathrm{b}}$ \\
\hline Ash & $0.02 \pm 0.00^{\mathrm{a}}$ & $0.01 \pm 0.00^{\mathrm{a}}$ & $0.01 \pm 0.00^{\mathrm{a}}$ \\
\hline Carbohydrate & $20.79 \pm 0.25^{\mathrm{a}}$ & $16.01 \pm 0.15^{\mathrm{b}}$ & $14.30 \pm 0.10^{\mathrm{c}}$ \\
\hline
\end{tabular}

Each value is means \pm SD of duplicates. Values with different superscript within the same row are significantly different $(p<0.05)$. SGP-Sugar sweetened popsicle, UDP-unroasted date sweetened popsicle, and RDP- roasted date sweetened popsicle

Table 3. pH, Titrable acidity (TTA) and Total soluble solids (TSS)

\begin{tabular}{|l|l|l|l|}
\hline Samples & $\mathrm{pH}$ & TTA $\%$ & TSS\% \\
\hline SGP & $7.06 \pm 0.01^{\mathrm{a}}$ & $0.18 \pm 0.00^{\mathrm{a}}$ & $22.09 \pm 1.62^{\mathrm{a}}$ \\
\hline UDP & $6.75 \pm 0.06^{\mathrm{b}}$ & $0.18 \pm 0.00^{\mathrm{a}}$ & $18.65 \pm 0.27^{\mathrm{b}}$ \\
\hline RDP & $6.74 \pm 0.06^{\mathrm{b}}$ & $0.18 \pm 0.00^{\mathrm{a}}$ & $16.47 \pm 0.02^{\mathrm{c}}$ \\
\hline
\end{tabular}

Each value is means \pm SD of duplicates. Values with the different superscript within the same column are significantly different $(\mathrm{p}<0.05)$. SGP-Sugar sweetened popsicle, UDP- unroasted date sweetened popsicle and RDP-roasted date sweetened popsicle

Table 4. Mineral Concentrations in Popsicles

\begin{tabular}{|l|l|l|l|}
\hline Mineral $(\mathrm{mg} / 100 \mathrm{~g})$ & SGP & UDP & RDP \\
\hline $\mathrm{Zn}$ & $2.45 \pm 0.01^{\mathrm{a}}$ & $2.41 \pm 0.01^{\mathrm{b}}$ & $2.40 \pm 0.00^{\mathrm{b}}$ \\
\hline $\mathrm{Fe}$ & $0.61 \pm 0.00^{\mathrm{a}}$ & $0.50 \pm 0.01^{\mathrm{b}}$ & $0.58 \pm 0.00^{\mathrm{a}}$ \\
\hline $\mathrm{Mn}$ & $0.07 \pm 0.00^{\mathrm{a}}$ & $0.09 \pm 0.00^{\mathrm{a}}$ & $0.08 \pm 0.00^{\mathrm{a}}$ \\
\hline $\mathrm{Na}$ & $43.26 \pm 0.44^{\mathrm{a}}$ & $14.98 \pm 0.01^{\mathrm{c}}$ & $22.23 \pm 0.01^{\mathrm{b}}$ \\
\hline $\mathrm{K}$ & $9.12 \pm 0.01^{\mathrm{c}}$ & $9.91 \pm 0.07^{\mathrm{b}}$ & $10.25 \pm 0.01^{\mathrm{a}}$ \\
\hline $\mathrm{Ca}$ & $1.28 \pm 0.01^{\mathrm{b}}$ & $1.69 \pm 0.01^{\mathrm{a}}$ & $1.69 \pm 0.01^{\mathrm{a}}$ \\
\hline
\end{tabular}

Each value is means \pm SD of duplicates. Values with the different superscript within the same row are significantly different $(\mathrm{p}<0.05)$. SGP-Sugar sweetened popsicle, UDP- unroasted date sweetened popsicle and RDP- roasted date sweetened popsicle. 

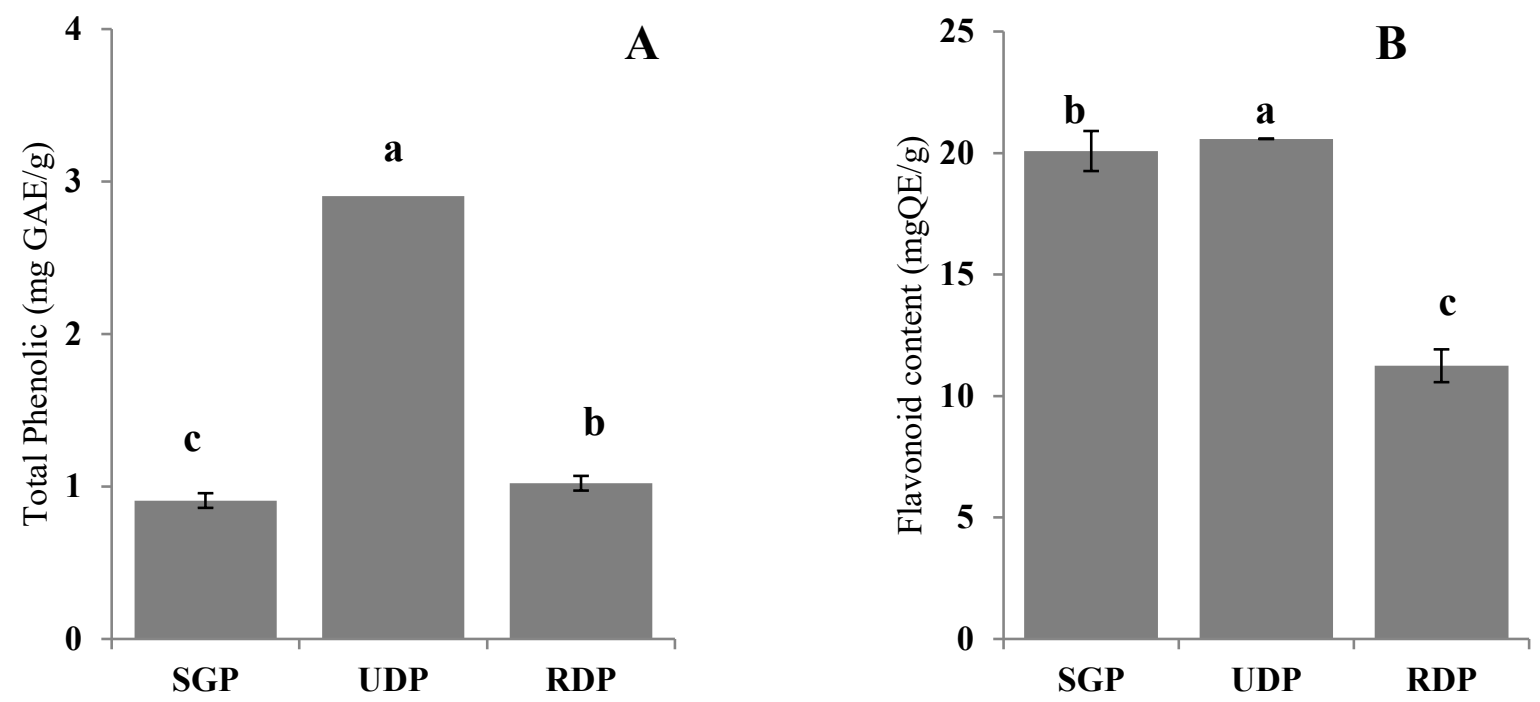

Figure 1. A.)Total phenolic content of popsicles (TPC) (mg GAE/g) and B.) Total Flavonoid content of popsicles (TFC) $(\mathrm{mg} \mathrm{QE} / \mathrm{g})$. Bars with same superscripts are not significantly different $(\mathrm{P}>0.05)$ SGP-Sugar sweetened popsicle, UDPunroasted date sweetened popsicle and RDP- roasted date sweetened popsicle.

Figure 2 shows the antioxidant capacities of the popsicles determined by DPPH, $\mathrm{ABTS}^{+}$and iron reducing tests. The capacity of an antioxidant to scavenge free radicals was evaluated with the DPPH assay, which was observed through the decrease in absorbance at $517 \mathrm{~nm}$ as the antioxidant traps the DPPH free radicals. The popsicles sweetened with unroasted date (UDP) $(78.75 \%)$ was observed to have the highest capacity to scavenge free radical while the least was demonstrated by sugar sweetened popsicles (SGP) $(17.32 \%)$. The antioxidant capacity of popsicles sweetened with roasted dates (RDP) was $18 \%$ lower than UDP but $50 \%$ higher than SGP samples. Similar results to DPPH were demonstrated for $\mathrm{ABTS}^{+}$test reported as $\mu \mathrm{mol}$ Trolox equivalent/g, with values of 74.7, 94.79 and 84.93 for SGP, UDP, and RDP respectively. The potency of bioactive compounds in a reduction reaction is linked to their electron donating ability and this indicates the antioxidant ability of the compound and determined by FRAP assay. Fig 2C shows UDP (2.25 mg AAE/g) has the highest reducing ability followed by RDP $(2.21 \mathrm{mg}$ $\mathrm{AAE} / \mathrm{g})$ while SGP (1.75 mg AAE/g) has the least reducing ability. The decrease in the antioxidant ability of RDP samples suggests a loss of bioactive components (TPC and TFC) during roasting. Studies of grains, nuts, fruits and vegetables have illustrated the positive correlation between total phenolic and antioxidant power (Oboh et al.,2010; Kornsteiner et al., 2006 and $\mathrm{Li}$ et al., 2009). Therefore the decrease in the antioxidant activity and phenolic compounds of the popsicles sweetened with roasted date (RDP) suggests that phenolics and flavonoids might be the crucial radical scavenger and reductant

\section{Melting rate}

Between 0-10 min, the popsicles showed similar melting behavior, although resistance to melting was higher in SGP samples. The melting rate difference was distinguishable at $20 \mathrm{~min}$. with RDP samples showing lower melting rate compared to SGP and UDP. This also implied a longer melting time and greater melting resistance for popsicles sweetened with roasted dates (RDP). The resistance of the popsicles to melting until the point of first drip (5 $\mathrm{min}$ ) was due to the viscosity generated by hydrocolloids (CMC) used in the preparation. The formation of compound during roasting process might also be responsible for the sustainable resistance to melting in the RDP samples. Disintegration of the popsicles within the studied period was uniform for all the samples.

\section{Sensory evaluation}

This present study revealed that popsicles containing roasted dates (RDP) had higher sensory scores in the attributes including aroma, taste, flavour, aftertaste and overall consumer acceptance compared to SGP and UDP (Table 5). However, RDP was not significantly different in appearance, color and aftertaste from the UDP popsicles. The overall choice for popsicles sweetened with roasted dates (RDP) was attributed to the taste, flavour and aroma as compared to the sugar and unroasted date sweetened popsicles. Roasting is a heat process that enhances the flavour, taste and colour of food products. 

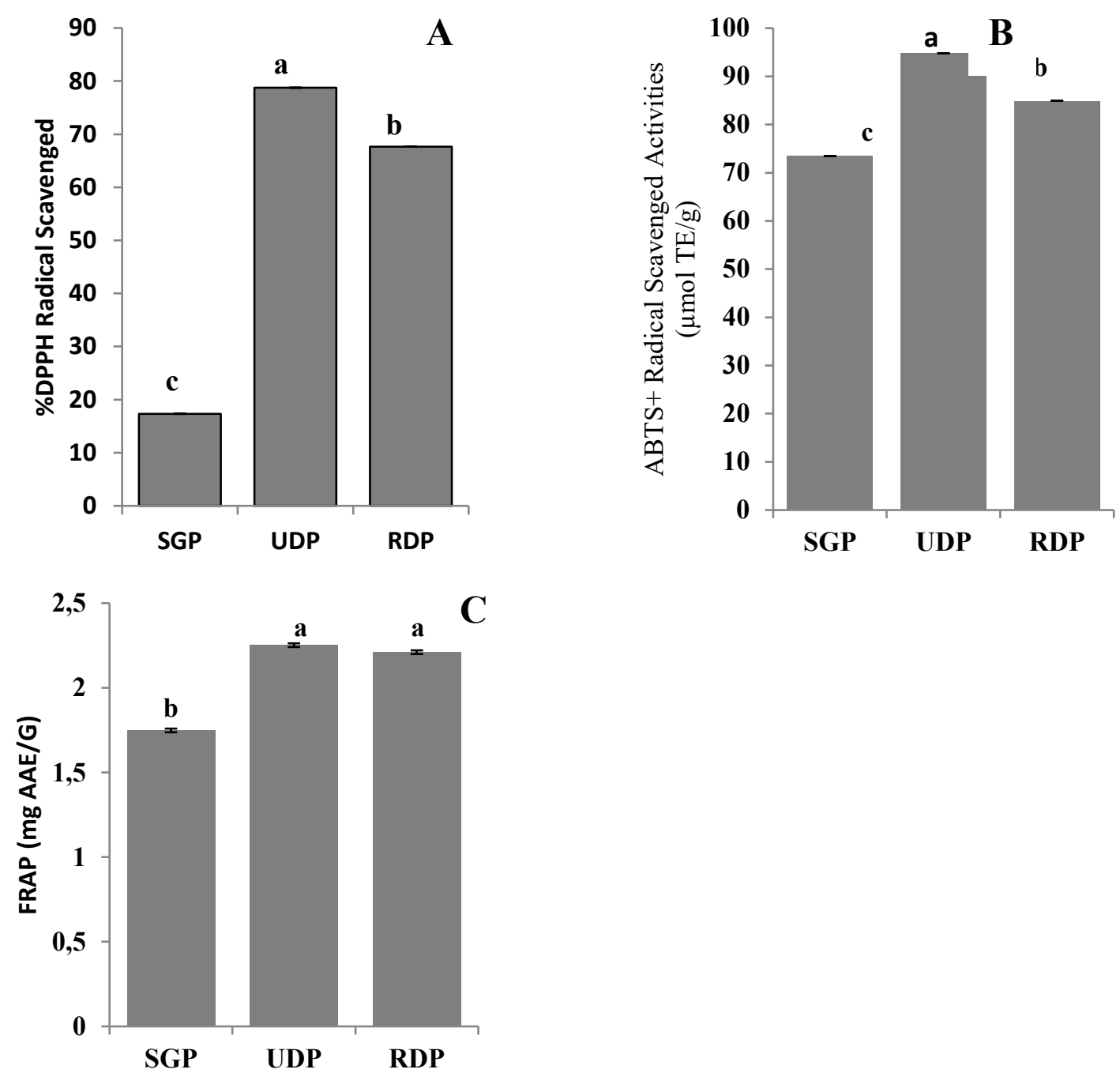

Figure 2. Antioxidant activity of Popsicles. A.) \% DPPH of Popsicles. B.) ABTS ${ }^{+}$of Popsicles ( $\mu$ molTE/g).C.) FRAP of Popsicles (mg AAE/g). Bars with different superscripts are significantly different $(\mathrm{P}<0.05)$ SGP-Sugar sweetened popsicle, UDP- unroasted date sweetened popsicle, RDP- roasted date sweetened popsicle.

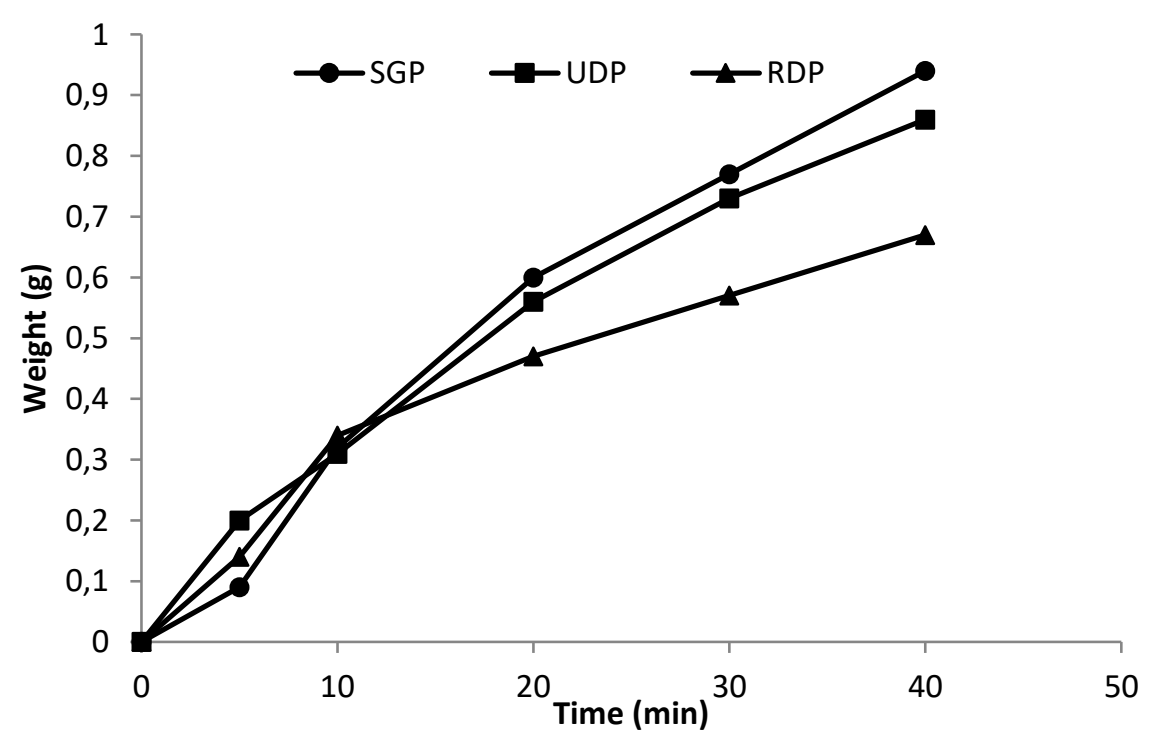

Figure 3 Melting behavior with different samples of Popsicle. SGP-Sugar sweetened popsicle, UDP- unroasted date sweetened popsicle, RDP- roasted date sweetened popsicle. 
Table 5. Results of Sensory evaluation of popsicles

\begin{tabular}{|l|l|l|l|}
\hline Sample & SGP & UDP & RDP \\
\hline Appearance & $7.20 \pm 0.21^{\mathrm{a}}$ & $6.20 \pm 0.30^{\mathrm{b}}$ & $6.25 \pm 0.39^{\mathrm{b}}$ \\
\hline Colour & $7.10 \pm 0.27^{\mathrm{a}}$ & $6.15 \pm 0.34^{\mathrm{b}}$ & $6.55 \pm 0.33^{\mathrm{ab}}$ \\
\hline Aroma & $6.50 \pm 0.22^{\mathrm{a}}$ & $6.05 \pm 0.28^{\mathrm{b}}$ & $6.90 \pm 028^{\mathrm{a}}$ \\
\hline Taste & $6.00 \pm 0.30^{\mathrm{b}}$ & $5.80 \pm 0.32^{\mathrm{c}}$ & $7.00 \pm 0.32^{\mathrm{a}}$ \\
\hline Flavor & $6.45 \pm 0.27^{\mathrm{ab}}$ & $5.50 \pm 0.29^{\mathrm{b}}$ & $6.65 \pm 0.33^{\mathrm{a}}$ \\
\hline Aftertaste & $6.20 \pm 0.31^{\mathrm{a}}$ & $6.00 \pm 0.26^{\mathrm{a}}$ & $6.55 \pm 0.26^{\mathrm{a}}$ \\
\hline Overall acceptance & $6.45 \pm 0.29^{\mathrm{ab}}$ & $5.80 \pm 0.35^{\mathrm{b}}$ & $7.00 \pm 0.32^{\mathrm{a}}$ \\
\hline
\end{tabular}

Each value is means \pm SD of duplicates. Values with the same superscript within the same row are not significantly different $(\mathrm{p}>0.05)$. SGP-Sugar sweetened popsicle, UDP- unroasted date sweetened popsicle and RDP- roasted date sweetened popsicle

\section{CONCLUSIONS}

The findings in this study demonstrated the potential of using dates as alternative sweeteners for popsicles production. Date palm enhanced the presence of bioactive compounds in the popsicles which might also be a great means of assessing antioxidants with health benefits. Sensory attributes in terms of taste, flavour and aroma was improved with the application of roasted date palm fruit. Lower melting resistance was observed in sugar sweetened popsicles while the roasted and unroasted date increased the melting resistance of the popsicles. Higher melting resistance is a desirable characteristic for a popsicles. The utilization of date palm in the roasted or unroasted form for the production of popsicles is a great way of improving on the nutritional and sensory qualities of traditional popsicles that is sweetened by adding sugar.

\section{REFERENCES}

1. Al Farsi, M.A \& Lee, C.Y. (2008). Nutritional and functional properties of dates: a review. Critical Reviews in Food Science and Nutrition, 48, 877-887. DOI: 10.1080/10408390701724264.

2. Association of Official Analytical Chemists (AOAC) (2005). Association of Official Analytical Chemists. Official Methods of Analysis, 16th edition, Washington DC, USA.

3. Association of Official Analytical Chemists (AOAC) (2012). Association of Official Analytical Chemists. Official Methods of Analysis, 25th edition, Washington DC, USA

4. Borchani, C., Besbes, S., Blecker, C., Masmoudi, M., Baati, R. \& Attia, H. (2010). Chemical properties of 11 date cultivars and their corresponding fiber extracts. African Journal of Biotechnology, 9(26), 4096-4110.

5. Chang, C., Yang, M., Wen, H. \& Chern, J. (2002). Estimation of total flavonoids content in propolis by two complementary colorimetric methods. Journal of Food and Drug Analysis, 10(3), 178-182.

6. Choe, E., \& Min, D.B. (2008). Mechanisms and factors for edible oil oxidation. Comprehensive Reviews in Food Science and Food safety, 5, 169-186. DOI: 10.1111/j.1541-4337.2006.00009.x

7. El Sohaimy, S.A., Abdel Wahab, A.E., Brennan, C.S. \& Aboulenein, A.M. (2015.) Phenolic content, antioxidant and antimicrobial activities of Egyptian date palm (Phoenix dactylifera L.) fruits. Australian Journal of Basic and Applied Science, 9(1), 141-147.

8. FAO (2003). Food energy: Methods of analysis and conversion factors Food and Paper Nutrition Paper Rome: FAO, 18-37

9. Gajo A.A., de Resende J.V., Costa F.F., Pereira C.G., de Lima R.R., Antonialli F., and de Abreu L.R.( 2017). Effect of hydrocolloids blends on frozen dessert "popsicles" made with whey concentrated.

LWT-Food Science and Technology, 75, 473-480. DOI: 10.1016/j.lwt.2016.09.027

10. Georgé, S., Brat, P., Alter, P., \& Amiot, M. J. (2005). Rapid determination of polyphenols and vitamin $\mathrm{C}$ in plant-derived products. Journal of Agricultural and Food Chemistry,53, 1370-1373. DOI: 10.1021/jf048396b

11. Granger, C., Leger, A., Barey, P., Langendorff, V., \& Cansell, M. (2005). Influence of formulation on the structural networks in ice cream. International Dairy Journal, 15, 255-262. DOI:

10.1016/j.idairyj.2004.07.009 
12. Gyamfi, M.A., Yonamine, M., \& Aniya, Y. (1999). Free-radical scavenging action of medicinal herbs from Ghana: Thonningia sanguinea on experimentally-induced liver injuries. General Pharmacology, 32(6), 661-667. DOI: 10.1016/S0306-3623(98)00238-9

13. Irondi, E.A., Adegoke B.M., Effion, E.S., Oyewo, S.O., Alamu, E.O. \& Boligon, A.A. (2019). Enzymes inhibitory property, antioxidant activity and phenolics profile of raw and roasted red sorghum grains in vitro. Food Science and Human Wellness 8(2), 142-148, DOI: 10.1016/j.fshw.2019.03.012

14. Kornsteiner, M., Karl-Heinz, W. \& Elmadfa, I. (2006).Tocopherols and total phenolics in 10 different nut types. Food Chemistry, 98(2), 381-387. DOI: 10.1016/j.foodchem.2005.07.033

15. Lemos, M.R., Siqueira, E.M., Arruda, S.F. \& Zambiazi, R.C. (2012). The effect of roasting on the phenolic compounds and antioxidant potential of baru nuts [Dipteryx alataVog.]. Food Research International, 48(2), 592-597. DOI: 10.1016/j.foodres.2012.05.027

16. Li, H., Wang, X., Li, Y., Li, P. \& Wang, H. (2009). Polyphenolic compounds and antioxidant properties of selected China wines. Food Chemistry, 112(2), 454-460. DOI: 10.1016/j.foodchem.2008.05.111

17. Martins, C. P. C., Ferreira, M. V. S., Esmerino, E. A., Moraes, J., Pimentel, T. C., Rocha, R. S., Freitas, M. Q., Santos, J. S., Senaka Ranadheera, C., Rosa, L. S., Teodoro, A. J., Mathias, S. P., Silva, M. C., Raices, R. S. L., Couto, S. R. M., Granato, D. and Cruz, A. G. (2018). Chemical, sensory, and functional properties of wheybased popsicles manufactured with watermelon juice concentrated at different temperatures. Food Chemistry, 255, 58-66. DOI: 10.1016/j.foodchem.2018.02.044

18. Ndife, J., Obiegbunna, J. \& Ajayi, S. (2013) Comparative Evaluation of the Nutritional and Sensory Quality of Major Commercial Whole-Wheat Breads In Nigerian Market. Advance Journal of Food Science and Technology, 5, 1600-1605. DOI:10.19026/ajfst.5.3395

19. Oboh, G., Ademiluyi, A.O. \& Akindahunsi, A.A. (2010).The effect of roasting on the nutritional and antioxidant properties of yellow and white maize varieties. International Journal of Food Science and Technology, 45(6), 1236-1242. DOI: 10.1111/j.1365-2621.2010.02263.x

20. Olivero, T., Capuano, E., Cammerer, B. \& Fogliano, V. (2009). Influence of roasting on the antioxidant capacity and HMF formation of a cocoa bean model systems. Journal of Agriculture and Food Chemistry, 57, 147-152. DOI: 10.1021/jf802250j

21. Oracz, J. \& Nebesny, E. (2018). Effect of roasting parameters on the physicochemical characteristics of high molecular weight mallard reaction products isolated from cocoa beans of different Theobroma cacao L.group). European Food Research and Technology, 245(1), 111-128. DOI: 10.1007/s00217018-3144-y

22. Oyaizu, M. (1986).Studies on products of browning reactions: antioxidative activities of browning reaction prepared from glucosamine. The Japanese Journal of Nutrition and Dietetics, 44, 307-315. DOI: $10.12691 / \mathrm{jfnr}-6-7-3$.

23. Re, R., Pellegrini, N., Proteggente, A., Pannala, A., Yang, M. \& Rice-Evans, C. (1999). Antioxidant activity applying an improved ABTS radical cation decolorisation assay. Free Radical Biology and Medicine, 26(9-10), 1231-1237. DOI: 10.1016/S0891-5849(98)00315-3

24. Soukoulis, C., Chandrinos, I., \&Tzia, C. (2008). Study of functionality of selected hydrocolloids and their blends with k-carrageenan on storage quality of vanilla ice cream. LWT-Food Science and Technology, 141, 1816-1827. DOI: 10.1016/j.1wt.2007.12.009

25. Taylor, J. R. N. \& Duodu, K. G. (2015). Effects of processing sorghum and millets on

26. their phenolic phytochemicals and the implications of this to the health enhancing properties of sorghum and millet food and beverage products. Journal of the Science of Food and Agriculture, 95, 225-227. DOI: $10.1002 /$ jsfa.6713

27. Vignoli, J.A., Viegas, M.C., Bassoli, D.G. \& Benassi, M.D. (2014). Roasting process affects differently the bioactive compounds and the antioxidant activity of arabica and robusta coffees. Food Research International, 61: 279-285. DOI: 10.1016/j.foodres.2013.06.006 